\title{
Acceptance Study on the Usage of Health- Enabling Technologies in Therapy and Diagnostics for People with Mental Disorders
}

\author{
Bastian DROEGEMUELLER ${ }^{\mathrm{a}, 1}$, Corinna MIELKE ${ }^{\mathrm{a}}$, \\ Reinhold HAUX ${ }^{\mathrm{a}}$ and Alexander DIEHL ${ }^{\mathrm{b}}$ \\ ${ }^{a}$ Peter L. Reichertz Institute for Medical Informatics of TU Braunschweig and \\ Hannover Medical School, Braunschweig, Germany \\ ${ }^{b}$ Department of Psychiatry, Psychotherapy and Psychosomatics, Braunschweig \\ Medical Center, Germany
}

\begin{abstract}
Mental disorders are widespread among the world's population and place a high burden on both the people affected and the economy. In this area of health care and prevention major deficits can be found. Health-enabling technologies are being developed in order to provide support in the therapy and diagnostics of mental disorders. However, it is not clear whether patients are open to these technologies and what they expect from a suitable usage. The main goal of this study is to find out what opinions, hopes and fears mentally ill persons have towards a supporting treatment with health-enabling technologies. Personal interviews were conducted with psychiatric patients for that purpose. The evaluation of the interview data revealed a predominantly positive mindset of the participants. In addition to the general question according to the acceptance, requirements and expectations for the use of health-enabling technologies were acquired. In this context the concern of an invasion of privacy was exposed as a major barrier.
\end{abstract}

Keywords. Mental disorders, mentally ill persons, health-enabling technologies, patient acceptance of health care, data collection, interview, expectations

\section{Introduction}

Mental illness is becoming increasingly relevant within our society. Not only the proportion of disability to work and the number of 'Disability-Adjusted Life Years' (DALY) caused by these disorders is increasing, but also the associated economic loss through direct and indirect costs $[1,2]$. On the other hand, there is an acute medical shortage for patients due to a lack of medical specialists and nursing staff [3]. In order to reduce the burden on the health care system, it is becoming increasingly common to use health-enabling technologies, for example ambient assisted living systems for the elderly. Comparable sensors and technologies are now supposed to be used to support

${ }^{1}$ Corresponding Author, Bastian Droegemueller, Peter L. Reichertz Institute for Medical Informatics (PLRI), University of Braunschweig - Institute of Technology and Hannover Medical School, Mühlenpfordtstr. 23, D-38106 Braunschweig; E-mail: b.droegemueller@tu-braunschweig.de. 
planned therapies or the general life of patients in psychiatric treatment $[4,5]$. A literature search using PubMed showed that only a few studies could be found that deal with this exact topic. Therefore our assumption is that it is unclear whether psychiatric patients are openminded about the use of these technologies and what they expect from a supportive implementation. The overall objective of the study is to collect as many statements as possible from psychiatric patients in terms of their opinions, fears and hopes regarding therapy support by health-enabling technologies, so that first impressions about the general acceptance of these technologies can be derived. Studies with a similar starting point suggest that the acceptance is likely to be predominantly positive $[6,7,8]$. However, the concern about an intrusion into intimacy and privacy seems to be a major barrier to use [9]. In the state of research mentioned here, people with mental disorders are only a small part of the total study collective. Furthermore, many different technologies are usually considered there. In this study psychiatric patients are directly associated with healthenabling technologies in the form of both wearable and smart home sensors.

\section{Method}

In close cooperation with the Department of Psychiatry, Psychotherapy and Psychosomatics of the Braunschweig Medical Center, an acceptance study was conducted among psychiatric patients. For this study we used individual oral interviews with suitable patients. In our estimation, the patients did not suffer any disadvantages from participating in the study. In addition, there were no points of contact with the medical care and therapy of the patients, which is why we have refrained from involving the ethics committee.

\subsection{Design of the study}

A separate questionnaire was self-developed for the interviews, as no suitable questionnaire could be found in the literature for this specific topic. For the data collection the participants were asked a total of 13 questions. Most of these are of a quantitative nature. But there are also questions that required a qualitative answer. Previous experiences with health-enabling technologies were enquired in the interview as well as opinions on the possible use of wearable and smart home sensors. Therefore imaginable expectations and requirements were collected from the patients. Due to the different types of questions, the data evaluation consists of qualitative (e.g. clustering of similar answers) and quantitative methods, like the descriptive analysis. All in all, 15 to 20 minutes were set for conducting a single interview.

\subsection{Details of the study population}

When selecting patients, care was taken to ensure that the study population was reasonably limited. For this task we defined the following main inclusion and exclusion criteria. 
Inclusion criteria:

- The potential participant must be diagnosed with a mental disorder - according to ICD-10 F00-F99 'Mental and behavioural disorders'

- The potential participant must be cognitively and mentally able to participate in the study

\section{Exclusion criteria:}

- The potential participant is not able to participate in the study due to the severity of the mental illness (e.g. psychoses or suicidal tendencies)

After the recruitment process, the study collective resulted in a size of $n=27$. Table 1 shows an overview of the characterization of the study participants. Due to the high number of individual diagnoses, the groups 'F30-F39' and 'Other' were considered in the further study.

Table 1. Characterization of the study participants per interview

\begin{tabular}{|c|c|c|c|c|c|c|c|c|c|}
\hline Interview & Age & Gender & $\begin{array}{l}\text { Diagnosis } \\
\text { (ICD-10) }\end{array}$ & $\begin{array}{c}\text { Consideration } \\
\text { within the study }\end{array}$ & Interview & Age & Gender & $\begin{array}{l}\text { Diagnosis } \\
\text { (ICD-10) }\end{array}$ & $\begin{array}{l}\text { Consideration } \\
\text { within the study }\end{array}$ \\
\hline 1 & $25-34$ & $\mathrm{~m}$ & F34.1 & F $30-F 39$ & 15 & $35-44$ & $\mathrm{~m}$ & F 32.2 & F30-F39 \\
\hline 2 & $18-24$ & $\mathrm{~m}$ & F 20.0 & other & 16 & $60-69$ & f & F 32.2 & F30-F39 \\
\hline 3 & $35-44$ & $\mathrm{~m}$ & F 33.2 & F30-F39 & 17 & $25-34$ & $\mathrm{~m}$ & F 32.2 & F30-F39 \\
\hline 4 & $35-44$ & f & F 33.1 & F30-F39 & 18 & $18-24$ & $\mathrm{~m}$ & F 33.2 & F30-F39 \\
\hline 5 & $45-59$ & f & not specified & not specified & 19 & $18-24$ & f & $\mathrm{F} 60.3$ & other \\
\hline 6 & $25-34$ & $f$ & F 32.2 & F30-F39 & 20 & $25-34$ & $f$ & F 32.2 & F30-F39 \\
\hline 7 & $35-44$ & $\mathrm{~m}$ & F33.2 & F30-F39 & 21 & $45-59$ & $f$ & $\mathrm{~F} 41.0$ & other \\
\hline 8 & $45-59$ & $f$ & F00.2 & other & 22 & $45-59$ & $\mathrm{~m}$ & not specified & not specified \\
\hline 9 & $25-34$ & $\mathrm{~m}$ & F33.2 & F30-F39 & 23 & $60-69$ & f & F40.1 & other \\
\hline 10 & $25-34$ & $\mathrm{~m}$ & F 32.2 & F30-F39 & 24 & $60-69$ & f & F43.2 & other \\
\hline 11 & $60-69$ & $\mathrm{~m}$ & F 32.2 & F $30-F 39$ & 25 & $18-24$ & f & F 32.2 & F30-F39 \\
\hline 12 & $60-69$ & $\mathrm{~m}$ & F 32.2 & F30-F39 & 26 & $18-24$ & f & F 32.2 & $\mathrm{~F} 30-\mathrm{F} 39$ \\
\hline 13 & $70+$ & $\mathrm{m}$ & F 32.2 & F30-F39 & 27 & $18-24$ & f & F60.3 & other \\
\hline 14 & $70+$ & $\mathrm{f}$ & F32.1 & F30-F39 & - & - & - & - & - \\
\hline
\end{tabular}

\subsection{Implementation of the study}

The actual course of the study was largely similar to the previously developed study plan, which suggests that the planning was well thought out. The interviews were conducted in the period from mid-February to mid-March 2020 and the participants were distributed among a total of five different psychiatric wards of the Braunschweig Medical Center.

\section{Results}

For the study collective it can be stated that there is a predominant acceptance of the use of health-enabling technologies in therapy and diagnostics. By differentiating between age and type of mental disorder, almost no differences in basic consent are apparent. 
The gender-specific differences, on the other hand, can be seen in a slightly higher acceptance by male patients. In addition to that, it is noticeable that younger patients seem to be much more expectant and joyful when it comes to the application of those technologies. It can also be seen that for a large proportion of patients, the use of such technologies entails a fear of an excessive invasion of privacy. As expected, this concern can be understood as a major barrier to the use of these type of technologies.

Furthermore, the evaluation of the interviews made it possible to identify basic requirements for the use of health-enabling technologies. As it can be seen in figure 1, besides several functional and non-functional requirements, boundary conditions could be derived from the given answers.
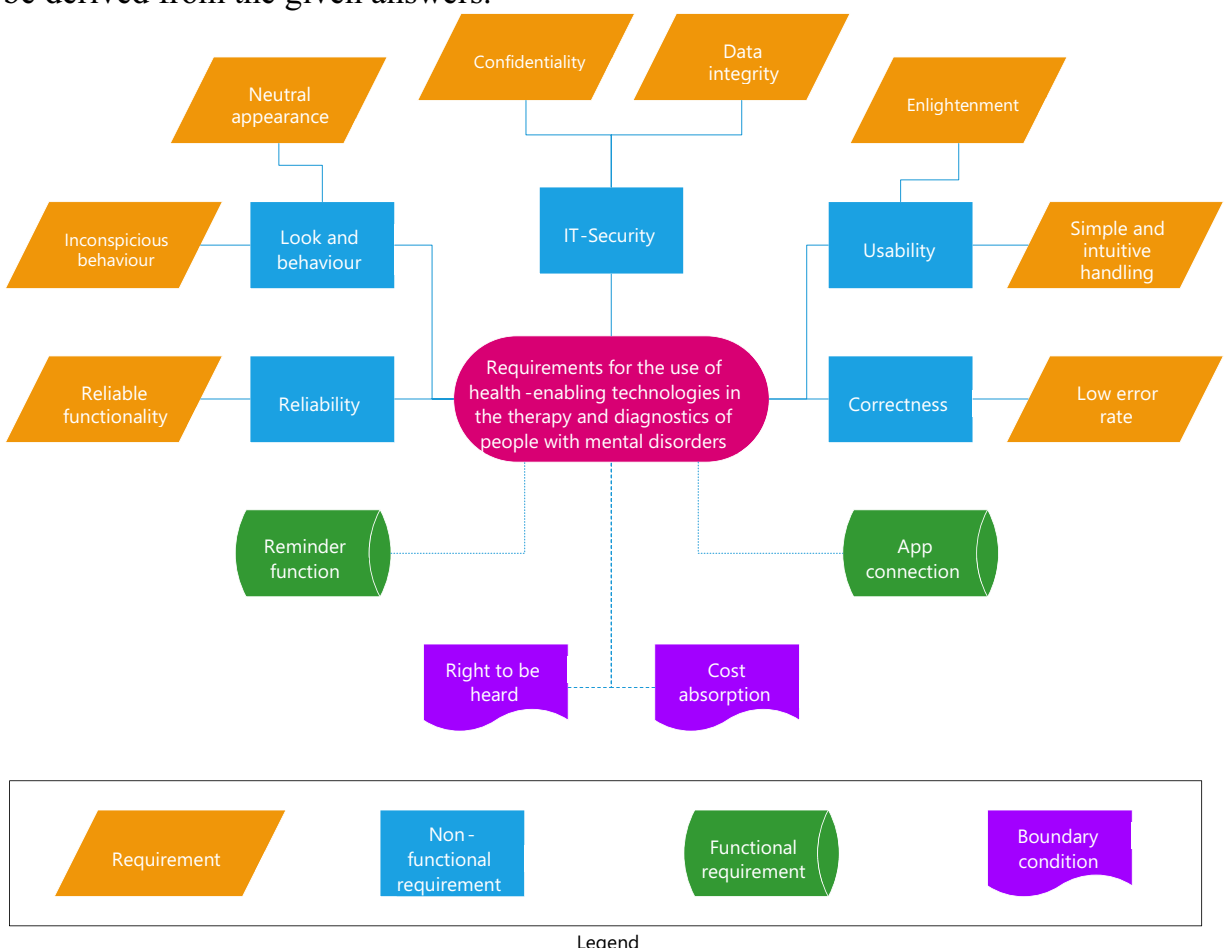

Figure 1. Requirements for the use of health-enabling technologies in the therapy and diagnostics of people with mental disorders

\section{Discussion}

\subsection{Limitations}

Since no suitable questionnaire could be found in the literature, a separate one had to be self-developed, which means that this questionnaire must be considered as not validated. This study is not free of limitations due to the time constraints. Because of the small study collective, it is recommended that in future acceptance studies a much higher number of participants should be interviewed. That would also make it possible to distinguish between different types of mental disorders. In addition to that, a greater 
inclusion of people at a higher age would be useful. During the recruitment process it was obvious that many of the elderly already refused to be informed about the study due to a lack of understanding of the technology. It is probable that the study's research collective largely comprises people who have a higher affinity for technology than a representative population. This assumption has to be counteracted in future studies.

\subsection{Conclusion}

With a size of $\mathrm{n}=27$, the study collective is too small to draw thematically meaningful conclusions regarding a differentiated consideration of the individual disorders. In this case, an acceptance study should again be conducted on the basis of a modified study plan. But the results of the study allow a first impression about the general acceptance of patients regarding the use of appropriate technologies. Overall, the results fit very well into the latest state of the art. Not only the assumption after a predominant acceptance could be substantiated here $[6,7,8]$, but also the fear about an intrusion into intimacy and privacy, which is also described in a previous study [9]. The investigation that took place here made it possible to set a focus whose content statements can supplement the previous findings of the literature. In this context, the concept of this acceptance study can also serve as a helpful support for further studies. For this purpose, the study implementation, in connection with the identified limitations, offers a practical example in research on the acceptance of psychiatric patients with regard to the use of healthenabling technologies in therapy and diagnostics.

\section{References}

[1] Plass D, Vos T, Hornberg C, Scheidt-Nave C, Zeeb H, Kramer A. Trends in disease burden in Germany: results, implications and limitations of the Global Burden of Disease Study. Dtsch Arztebl Int. 2014 Sep; 111(38): 629-38.

[2] Trautmann S, Rehm J, Wittchen HU. The economic costs of mental disorders: Do our societies react appropriately to the burden of mental disorders. EMBO Rep. 2016 Sep; 17(9):1245-1249.

[3] Butryn T, Bryant L, Marchionni C, Sholevar F. The shortage of psychiatrists and other mental health providers: Causes, current state, and potential solutions. Int J Acad Med. 2017 Jul; 3:5-9.

[4] Haux R, Koch S, Lovell NH, Marschollek M, Nakashima N, Wolf KH. Health-Enabling and Ambient Assistive Technologies: Past, Present, Future. Yearb Med Inform. 2016 Jun 30; 1:76-91.

[5] Doraiswamy PM, London E, Varnum P, Harvey B, Saxena S, Tottman S, Campbell P, Ibanez F, Manji H, Al Olama MAAS, Chou I, Herman H, Jeong SJ, Le T, Montojo C, Revel B, Rommelfanger KS, Stix C, Thakor N, Chow KHM, Welchman AE, Candeias V. Empowering 8 Billion Minds: Enabling Better Mental Health for All via the Ethical Adoption of Technologies. NAM Perspectives. 2019 Oct 28; 28 p.

[6] Wallbaum T, Frenken M, Meyer J, Hein A. Acceptance of sensor networks by dementia patients. Berlin: VDE Verlag GmbH. 2014 Jan 22; 7 p.

[7] Botros A, Schutz N, Camezind M, Urwyler P, Bolliger D, Vanbellingen T, Kistler R, Bohlhalter S, Muri RM, Mosimann UP, Nef T. Long-Term Home-Monitoring Sensor Technology in Patients with Parkinsons Disease - Acceptance and Adherence. MDPI. 2019 Nov 26. 1:1-13.

[8] Botella C, Mira A, Moragrega I, Garcia-Palacios A, Bretopn-Lopez J, Castilla D, Lopez del Amo AR, Soler C, Molinari G, Quero S, Gullien-Botella V, Miralles I, Nebot S, Serrano B, Majoe D, Alcaniz M, Banos RM. An Internet-based program for depression using activity and physiological sensors: efficacy, expectations, satisfaction, and ease of use. Dove Press Journal: Neuropsychiatric Disease and Treatment. 2016 Feb 23. 12:393-406.

[9] Patientenprojekte GmbH. Patientenperspektiven 2018 - Qualitative Studie zur Digitalisierung im Gesundheitswesen aus Sicht von Patientinnen und Patienten in Deutschland. Berlin: Kassenarztliche Bundesvereinigung (KBV); 2018 Aug. 39 p. German. 